\title{
CORRESPONDÊNCIA, GÊNERO E IMAGENS: PENSANDO A TRAJETÓRIA DA PINTORA ARTEMÍSIA LOMI GENTILESCHI
}

\author{
CORRESPONDENCE, GENDER AND IMAGES: THINKING THE \\ TRAJECTORY OF THE PAINTER ARTEMÍSIA LOMI GENTILESCHI
}

DOI: http://dx.doi.org/10.15448/2178-3748.2016.1.20290

\author{
Cristine Tedesco \\ Doutoranda - UFRGS \\ tedesco.cristi@gmail.com
}

\begin{abstract}
RESUMO: Este artigo integra um estudo sobre a trajetória de vida de Artemisia Lomi Gentileschi (1593-1654), por meio do qual buscamos entender sua atuação como mulher e como pintora. Trabalhamos com a produção pictórica de Artemisia, destinada principalmente à Corte da família Medici de Florença, e com sua correspondência, endereçada a negociantes de suas obras - entre eles mercadores, diplomatas, duques, membros de academias de arte e mecenas da Península Itálica. Ao analisarmos as fontes escritas e imagéticas fomos norteados por um questionamento: se o sujeito se constrói e se representa na escrita, poderia fazê-lo também em imagens? Além disso, o artigo se propõe a pensar como as questões de gênero se configuram na escrita e na obra pictórica de Artemisia Lomi Gentileschi. Realizamos uma investigação atrelada às discussões de gênero, pois entendemos que as relações de poder entre o feminino e o masculino são construídas culturalmente e que as identidades de homens e mulheres possuem origens sociais (SCOTT, 1990).
\end{abstract}

PALAVRAS-CHAVE: Trajetória de vida. Correspondência. Relações de gênero. Imagens.

ABSTRACT: This article integrates a study about the life trajectory of Artemisia Lomi Gentileschi (15931654), in which we seek to understand her acting as a woman and as a painter. We work with the pictorial production of Artemisia, destined mainly to the Court of Medici, in Florence, and her correspondence, addressed to dealers of her works - among them merchants, diplomats, dukes, members of art academies and patrons from the Italian Peninsula. By analyzing the written and imagetic sources we were guided by a question: if the subject builds and represents himself in the writing, could he do the same in images? Furthermore, the article proposes to think about how the questions of gender configure themselves in the writing and in the pictorial work of Artemisia Lomi Gentileschi. We made an investigation connected to the discussions of gender as we understand that the relations of power between the masculine and the feminine are culturally built and the identities of men and women have social origins (SCOTT, 1990).

KEYWORDS: Life trajectory. Correspondence. Gender relations. Images.

\section{INTRODUÇÃO}

A reflexão desenvolvida no presente texto está inserida na pesquisa sobre a trajetória de vida da pintora Artemisia Lomi Gentileschi (1593-1654) - filha primogênita do casal Orazio Gentileschi e Pudenzia Montore. Artemisia trabalhou no ateliê do pai, junto à residência da família em Roma, moendo pigmentos, misturando cores, fazendo pincéis, 
preparando superfícies ou ainda como modelo para as produções do pai. Foi também nesse contexto que pintou uma de suas telas mais conhecidas, "Susana e os velhos"1 (1610).

Nossa reflexão possui um recorte temporal que privilegia o período a partir do qual Artemisia se estabelece na cidade de Florença, no ano de 1613, evento significativo para sua atuação como pintora. Na cidade florentina o tio, Aurelio Lomi, apresentou-a a corte de Cosme II de Medici. A jovem artista adotou o sobrenome do tio passando a assinar Artemisia Lomi. A vida na corte se revelou uma experiência importante para o seu futuro: estabeleceu relações com representantes da nobreza, da política e das artes. Foi nesse período que conheceu Michelangelo Buonarroti, o Jovem, Francesco Maria Maringhi, Galileu Galilei, entre outros membros do círculo de intelectuais e artistas que tinham sido reunidos pelo GrãoDuque Cosme II de Medici, com quem Artemisia viria a trocar correspondência no futuro.

As cartas de Artemisia, são fontes importantes para a produção do conhecimento histórico e trazem contribuições significativas para entender o período. A correspondência da pintora indica que a maior parte de suas obras foram encomendas particulares. Além disso, a artista quase sempre recebia adiantamentos pelos trabalhos, mesmo quando atrasava as entregas. É possível que muitas obras de Artemisia ainda sejam desconhecidas para os pesquisadores, já que podem estar em posse de colecionadores particulares.

O problema levantado pela pesquisa é entender, em que medida estas cartas escritas entre os anos de 1617 e 1651 por Artemisia, seu marido e os colecionadores de suas obras contribuem para o estudo de sua trajetória como mulher e como pintora. Além disso, as cartas são fontes relevantes para explicar o cotidiano do mundo dos artistas do século XVII. Um mundo masculinizado no qual Artemisia, enquanto mulher, precisou lutar contra as desigualdades de gênero, como o fizeram outras mulheres pintoras de seu tempo, a exemplo de Lavínia Fontana (1552-1614) e Sofonisba Anguissola (1531-1621).

Além do trabalho com as cartas de Artemisia, o estudo também desenvolve uma reflexão com algumas obras pictóricas produzidas pela artista, a partir das quais se pode pensar e problematizar o contexto histórico do século XVII na Península Itálica. Nos filiamos ao método de Ulpiano B. T. de Meneses (2012), pois nos utilizaremos das potencialidades visuais das imagens artísticas como fonte para a pesquisa e, consequentemente, para escrita da história. Nesse sentido, pensar os efeitos da dimensão visual requer considerar que as imagens não apenas representam o passado, mas também ajudam a construí-lo.

\footnotetext{
${ }^{1}$ Susanna e i vecchioni (1610). Firmata e datata: “Arte [Misia] Gentileschi F/1610”. Óleo sobre tela, 170 x 119 $\mathrm{cm}$. Acervo do Castelo Weissenstein, Pommersfelden, Alemanha.
} 


\section{DO ESQUECIMENTO AO RECONHECIMENTO: COMO SE CONSTRUÍRAM AS VISÕES SOBRE ARTEMISIA LOMI GENTILESCHI}

Para entender como se construíram determinadas percepções sobre Artemisia Lomi Gentileschi (1593-1654), analisaremos a bibliografia produzida a partir da segunda metade do século XIX e início do XX, na qual a pintora é lembrada pela ótica do escândalo público que o processo crime intitulado "Estupro e libidinagem",2, significou. O processo foi realizado na cidade de Roma, em 1612; é composto por uma súplica de Orazio Gentileschi ${ }^{3}$ - pai de Artemisia - requerendo ao Pontífice Paulo V (Camilo Borghese) a abertura do processo, interrogatórios, declarações, acareações, depoimentos e um despacho saneador. A súplica de abertura do processo denunciava o pintor Agostino Tassi ${ }^{4}$ pelo desvirginamento forçado de Artemisia, no ano anterior (1611). A publicação dos documentos do processo penal contra Tassi repercutiu sobre a vida de Artemisia em Roma. A pintora foi lembrada pela ótica do escândalo público que o processo significou, o que não trouxe reconhecimento à sua pintura, que ainda hoje é conhecida apenas parcialmente, afirma Francesco Solinas (2011, p. 8).

Após a publicação do processo crime, em 1876, Roberto Longhi (1916) ensaiou uma análise sobre alguns quadros de Artemisia e Orazio Gentileschi. Para Longhi", a obra "Susana e os velhos", de 1610, teria sido em grande parte, se não no seu todo, produzida por Orazio e só assinada por Artemisia.

Entre os artistas do período Barroco que suscitaram maior interesse na última parte do século XX, estão Caravaggio, Rubens, Bernini, Van Dyck e Rembrandt. Artemisia aparece como menos qualificada, sua obra foi vista como modesta, exígua, provocando pouco interesse entre os pesquisadores. De acordo com Francesco Solinas (2011), atualmente Artemisia vem recuperando a posição de extrema relevância que ocupou durante sua vida.

Entre as décadas de 1960 e 1980, duas publicações importantes sobre Artemisia surgiram nos Estados Unidos. Ward Bissel (1968) e Mary Garrard (1989) iniciaram uma

\footnotetext{
${ }^{2}$ Stupri et Lenocinij Pro Curia et Fisco. In: MENZIO, Eva. (Org.). Lettere precedute da «Atti di un processo per stupro». Roma: Abscondita, 2004.

3 "Orazio Gentileschi nasceu em Pisa em 1563, sua família é florentina. Transferiu-se para Roma, provavelmente, em 1585. Em 1626 vai para a Inglaterra onde se torna pintor da corte. Morre em Londres em 1639". (MENZIO, 2004, pp. 109-110). (Tradução de minha autoria).

4 “Agostino Tassi nasceu em 1580, em Ponzano Romano. Transferiu-se para Roma, abandonou o sobrenome plebeu Buonamici e passou a utilizar o nome de seu protetor, marquês Tassi. Trabalhou Orazio Gentileschi no palácio papal de Monte Cavallo e no Casino delle Muse no palácio de Scipione no período em que ocorre o processo. Acusado de ter desvirginado Artemisia passa um ano detido na prisão Corte Savella". (MENZIO, 2004, pp. 109-110). (Tradução de minha autoria).

${ }^{5}$ Seu artigo intitulado Gentileschi padre e figlia [Gentileschi pai e filha] foi publicado em 1916 na revista L'Arte. (Tradução de minha autoria).
} 
reconstituição biográfica e trabalharam com sua obra pictórica, inaugurando uma nova perspectiva sobre Artemisia Lomi Gentileschi, que até então havia sido lembrada na pintura como mera discípula do pai.

O primeiro catálogo de que se tem conhecimento sobre Artemisia foi publicado em 1991, resultado da exposição realizada na Casa Buonarroti, em Florença. O evento foi idealizado por dois pesquisadores italianos: Roberto Contini e Gianni Papi. Para Contini, Artemisia superou muitos colegas pintores de seu tempo, quando produziu a precoce tela "Susana e os velhos", em 1610. À personagem é atribuída uma postura composta de embaraço e repulsa, distante das descrições comuns das mulheres do período. A tela dava início a uma experiência estética distinta, declara Roberto Contini (1991, p. 110).

A contribuição de Gianni Papi para o mesmo catálogo é uma análise da obra "Judite e a criada" (1625), a qual, segundo o pesquisador, marca com plenitude o segundo período romano de Artemisia. De acordo com a análise de Papi (1991, p. 53), é após o retorno de Artemisia para Roma, em 1620, que a artista alcança seus resultados mais importantes na pintura. $\mathrm{O}$ autor salienta ainda que este foi um momento de intensa criatividade na produção de Artemisia. A exposição e o catálogo publicado na cidade de Florença, em 1991, iniciavam um processo de restauração da personalidade artística de Artemisia, principalmente por meio da análise de suas pinturas de perspectiva caravaggesca ${ }^{6}$.

O Musée Maillol de Paris também organizou uma exposição dedicada à Artemisia entre 14 de março e 15 de julho de 2012. Para exposição de Paris foi realizada uma cronologia da trajetória de Artemisia, desenvolvida pelo pesquisador Michele Nicolaci ${ }^{7}$. O quadro cronológico é relevante porque apresenta os principais eventos documentados sobre a atuação da pintora em Roma, Florença, Veneza, Nápoles e Londres.

No entanto, os estudos mais recentes sobre Artemisia Lomi Gentileschi foram publicados no catálogo resultante da exposição realizada no Palazzo Reale, em Milão, entre os anos de 2011 e 2012. As cinquenta pinturas de Artemisia produzidas na primeira metade do século XVII, reunidas nessa exposição, estão atualmente em acervos de museus, galerias de arte e coleções particulares em países como Itália, Alemanha, Inglaterra, Estados Unidos, Espanha, França, entre outros.

\footnotetext{
${ }^{6}$ Utilizamos ao longo do texto os termos: "caravaggesco", "caravaggismo" e "caravaggistas", pois não existe uma tradução literal para o português que possa definir o significado desses termos. Para saber mais sobre o caravaggismo na Itália, França, Espanha e Países Baixos, consultar: MOIR, Alfred. Caravaggisti: Italia. Art Dossier. Firenze, Giunti, n. 109, pp. 4-35, febbraio, 2001.

${ }^{7}$ Conferir na publicação eletrônica: MUSÉE MAILLOL. Artemisia: Pouvoir, glorie et passions d'une femme peintre 1593-1654. Paris, 14 mars 15 julet 2012. Disponível em: <http://www.museemaillol.com/wpcontent/uploads/2011/07/DP_EN_05-03.pdf> Acesso em 19 de março de 2015.
} 
Analisando a exposição de Milão o pesquisador Sandro Barbagallo (2011), declara: "Digamos que Artemisia representa a versão feminina de Caravaggio"8 (BARBAGALLO, 2011, p. 1). Para Barbagallo (2011), “A grandeza artística de Artemisia Gentileschi vai muito além de sua história pessoal e de estereótipos que sempre a acompanharam"9 (BARBAGALLO, 2011, p. 1).

Alberto Giovanni Biuso e Giuseppina Randazzo (2012), - diretores científicos de uma revista de filosofia ${ }^{10}$ - também escreveram sobre a importância desta exposição de Artemisia no Palazzo Reale. Os pesquisadores destacam alguns dos personagens presentes nas obras da artista. Musas e ninfas impertinentes; monjas orgulhosas e temíveis; senhoras audaciosas e poderosas; rainhas antigas - Cleópatra - e pecadoras - Madalena; alegorias da pintura, da música, da paz, da retórica, da fama; Betsabéia no banho, Judite degolando Holofernes, Jael cravando um prego na têmpora de Sísara, etc. Para os autores, mais marcante entre essas mulheres é a samaritana pela pose e olhar absolutamente cético discutindo com um Jesus que parece estar em apuros (BIUSO; RANDAZZO, 2012, p. 50).

A obra intitulada "Cristo e a samaritana ao poço" (1637) foi pela primeira vez exposta ao público na Mostra Artemisia ${ }^{11}$ de 2011-2012, conforme Luciano Arcangeli (2011). A imagem é um dos "grandes quadros" citados por Artemisia em duas cartas enviadas, durante o outono de 1637, de Nápoles para Roma, cujo destinatário era Cassiano dal Pozzo ${ }^{12}$. Para Luciano Arcangeli (2011), o quadro é um dos maiores trabalhos de Artemisia do primeiro período napolitano da artista, fase que termina com sua viagem para a Inglaterra, em 1638 aonde trabalhou com seu pai na realização de uma pintura no teto da Casa da Rainha (Queen's House de Inigo Jones) em Greenwich.

As pesquisas sobre Artemisia foram produzidas em sua grande maioria pelos campos da história da arte e da literatura. No Brasil a artista e sua produção pictórica ainda são pouco conhecidas. Contudo, conseguimos encontrar alguns trabalhos onde Artemisia aparece.

\footnotetext{
8 "Diciamo che Artemisia rappresenta la versione femminile di Caravaggio". (BARGABALLO, 2011, p. 1). Tradução e minha autoria.

9 "La grandezza artistica di Artemisia Gentileschi va ben oltre le sue vicende personali e i luoghi comuni che da sempre l'accompagnano”. (BARBAGALLO, 2011, p. 1).

${ }^{10}$ BIUSO, Alberto Giovanni; RANDAZZO, Giuseppina. Artemisia. Rivista di Filosofia Vita Pensata. Ano 2, n. 14, março de 2012, Milão, pp. 50-51. Disponível em <http://www.vitapensata.eu/vitapensata/wpcontent/uploads/2012/03/Rivista-Marzo_AGBGR_Artemisia.pdf> Acesso em 22 de abril de 2015.

${ }^{11}$ A Mostra Artemisia (2011-2012) foi uma exposição que deu lugar não apenas aos seus quadros com representações da violência, mas destacou sua produção e revelou que Artemisia sabia trabalhar, com grande qualidade, uma variedade de gêneros pictóricos e temas muito amplos. Cinquenta pinturas da artista romana apresentadas nesta exposição, pela primeira vez juntas em um espaço, junto às de seu pai (Orazio Gentileschi), tio (Aurelio Lomi) e de alguns pintores que trabalharam com ela, Simon Vouet, por exemplo, e quem fazia parte de sua oficina como Bernardo Cavallino (BIUSO; RANDAZZO, 2012, p. 50).

${ }^{12}$ (Lettere di Artemisia, 2011, nº 49, p. 117).
} 
Localizamos o artigo da pesquisadora da área da Educação Luciana Gruppelli Loponte (2002) intitulado: "Sexualidades, artes visuais e poder: pedagogias visuais do feminino", no qual a autora analisa como a sexualidade feminina é colocada em discurso através das imagens produzidas pela arte ocidental. Ao estudar as formas de representação do nu, Loponte (2002) salienta a obra "Susana e os velhos" (1610) de Artemisia. Para Loponte (2002), a personagem não está representando uma mulher passiva, submissa ou provocativa, é sim uma Susana aterrorizada pelos homens que a observam.

Uma pesquisa sobre a literatura produzida a partir de questões da trajetória de Artemisia está sendo desenvolvida por Miriam de Paiva Vieira ${ }^{13}$. Vieira realiza, desde 2012, um estudo intermidiático das interseções entre as mídias literatura, arquitetura e pintura. Dentro deste projeto, a autora selecionou dois romances: Artemisia, de Anna Banti (1947) e The passion of Artemisia, de Susan Vreeland (2002). O trabalho de Vieira consiste em analisar, do ponto de vista da literatura, como Artemisia é apresentada ao mundo contemporâneo pelas duas autoras. Para Vieira (2012),

Enquanto o foco do romance intitulado simplesmente Artemisia é a tentativa de superação da dor da autora, que se mistura com a trajetória de vida da pintora, o foco de A paixão de Artemisia é a maneira como essa trajetória de vida gira em torno do trabalho, a maior paixão da artista. (VIEIRA, 2012, p. 128).

A mesma autora comenta que ao visitar a exposição "Caravaggio e seus seguidores"14 recebeu um folheto publicado pelos organizadores do evento, onde é enfatizado: “A filha de Gentileschi, Artemisia, protagonista de tumultuados incidentes sentimentais e raro exemplo de mulher pintora, também recebeu 'influência' da linguagem de Caravaggio”. (VIEIRA, 2012, p. 119).

O mapeamento e análise da bibliografia produzida sobre Artemisia nos dão condições de dizer que, apesar da relevância dos estudos mais recentes, ainda é preciso avançar muito no que diz respeito à trajetória de vida da artista e sua importância para a história da presença

\footnotetext{
${ }^{13}$ Doutoranda em Letras no Programa de Pós-Graduação em Estudos Literários da UFMG.

${ }^{14}$ A mostra "Caravaggio e seus seguidores" realizada em São Paulo, Belo Horizonte e Buenos Aires em 2012, trouxe a maior exposição de Michelangelo Merisi e seus seguidores já vista na América Latina. Entre as telas que fazem parte da exposição estão obras de Artemisia e Orazio Gentileschi. "Madalena desmaiada" (16301640), única obra de Artemisia que a exposição trouxe para o Brasil, foi recentemente atribuída à artista, não carrega sua assinatura e foi produzida entre as décadas de 1630 e 1640, em Nápoles. A imagem retrata uma figura feminina com os seios desnudos, cabeça arqueada para trás, segurando uma caveira na altura do púbis. A tela atribuída à Artemisia, trazida para o Brasil na exposição "Caravaggio e seus seguidores", não é mencionada nos catálogos publicados em 1991 e 2011. Além disso, "Madalena desmaiada" já foi atribuída a outros pintores como Francesco Trevisani e Guido Cagnacci.
} 
feminina no mundo da criação pictórica, não apenas por ter uma produção que retratou diferentes mulheres protagonistas de suas próprias histórias, mas principalmente pelo atrevimento de se inserir num mundo masculinizado. Nesse sentido, nossa pesquisa corrobora com os estudos realizados na última década, principalmente na Itália e nos Estados Unidos da América, os quais têm mostrado que Artemisia construiu uma linguagem estética própria e anticonformista.

\section{QUESTÕES TEÓRICAS PARA PENSAR A TRAJETÓRIA DE ARTEMISIA}

Nosso trabalho se utiliza das concepções teóricas elaboradas por Joan Scott (1990). Utilizamos o conceito de gênero como categoria de análise histórica e o entendemos como um saber sobre a diferença sexual construída social e culturalmente. Além disso, pensamos que o feminino se situa no mesmo campo de poder onde diferentes atores sociais produzem efeitos de poder sutis e novos. Pensamos a personagem Artemisia Lomi Gentileschi como uma mulher que não está fora do social, fora da cultura, ela é produto e produtora de sentidos. Joan Scott (1990) indica, que os historiadores dos Estudos de Gênero, possuem um compromisso teórico bastante relevante, de explicar as razões pelas quais as relações de poder são construídas na sociedade, como funcionam e como mudam. A este respeito a autora destaca:

Os historiadores da arte abrem novas perspectivas no momento em que decifram as implicações sociais das representações pictóricas dos homens e das mulheres. Estas interpretações estão fundamentadas na ideia de que as linguagens conceituais empregam a diferenciação para estabelecer o sentido e que a diferença sexual é um modo principal de dar significado à diferenciação. (SCOTT, 1990, p. 16).

Para refletir sobre os usos da correspondência como fonte histórica, utilizamos as contribuições de Angela de Castro Gomes (2004). De acordo com a pesquisadora,

O que passa a importar para o historiador é exatamente a ótica assumida pelo registro e como seu autor a expressa. Isto é, o documento não trata de "dizer o que houve", mas de dizer o que o autor diz que viu, sentiu e experimentou, retrospectivamente, em relação a um acontecimento. (GOMES, 2004, p. 15).

Os estudos que se utilizam de correspondências para compreender um sujeito ou mesmo um contexto, devem considerar que escrever cartas exige tempo, disciplina, reflexão e 
confiança, conforme salienta Gomes (2004). A mesma autora lembra que ao escrever uma carta, "Há sempre uma razão para fazê-lo: informar, pedir, agradecer, desabafar, rememorar, consolar, estimular, comemorar, etc.” (GOMES, 2004, p. 19). Além dessas questões, em muitas das cartas de Artemisia são negociadas e discutidas as suas obras, o que nos revela sua intensa atuação como pintora na primeira metade do século XVII.

Segundo Angela de Castro Gomes (2004), trabalhar com cartas, assim como com outros documentos, implica procurar responder:

\begin{abstract}
Quem escreve/lê as cartas? Em que condições e locais elas foram escritas? Onde foram encontradas e como estão guardadas? Qual, ou quais os seus objetivos? Que temas envolvem? Como são explorados em termos de vocabulário e linguagem? Essas questões podem se multiplicar, chamando a atenção do analista para as importantes relações estabelecidas entre quem escreve, o que escreve, como escreve e o suporte material usado na escrita. (GOMES, 2004, p. 21).
\end{abstract}

Entendemos ainda, que a correspondência quando tratada como fonte/objeto constitui um lugar de sociabilidade e pode revelar a dinâmica do campo cultural de um dado período. (GOMES, 2004, p. 52). As cartas são vestígios de história, registros de um tempo. Contudo, Roger Chartier (1992) nos alerta de que as fontes não são testemunhos da realidade. São testemunhos de como o real foi pensado, escrito e dado a ver. Se o sujeito se constrói e se representa na escrita, poderia fazê-lo também em imagens? Nesse sentido, o artigo desenvolve uma reflexão sobre como as questões de gênero se configuram na escrita e na obra pictórica de Artemisia Lomi Gentileschi.

\title{
VESTÍGIOS DO PERCURSO DE ARTEMISIA EM CARTAS E IMAGENS
}

$\mathrm{Na}$ correspondência de Artemisia aparecem inúmeras questões como, moradias e alojamentos nos quais a família residiu, dificuldades de locomoção entre as regiões da Península Itálica, obras produzidas por Artemisia, questões sobre as figuras humanas presentes nas imagens, valores dos quadros, dificuldades de encontrar modelos para as pinturas, doenças e condições climáticas, que muitas vezes impediam a entrega das obras dentro dos prazos estabelecidos; as cartas documentam ainda questões sobre nascimentos e falecimentos precoces dos filhos de Artemisia. 
As cartas ${ }^{15}$ eram endereçadas aos negociantes de suas obras - entre eles mercadores, diplomatas, duques, membros de academias de arte e de famílias renomadas da Península Itálica. Dentre os negociantes das obras de Artemisia estão o Grão-Duque da Toscana Cosme II de Medici, Francesco Maria Maringhi, Cassiano del Pozzo, Duque de Modena Francesco I d'Este, Grão-Duque da Toscana Ferdinando II de Medici, Andrea Cioli, Antonio Ruffo e Galileu Galilei.

Os períodos da trajetória de Artemisia que abordamos no presente texto são a época na qual a pintora viveu em Florença a partir de 1613 e seu inesperado retorno a Roma em 1620. Sua ida de Roma para a cidade florentina ocorre após o casamento de conveniência organizado pelo pai, em função da situação na qual se encontrava Artemisia: "desvirginada/desonrada" e o fim do processo crime por desvirginamento encerrado, em Roma (1612), após cinco meses de interrogatórios e acareações.

A atuação de Artemisia como pintora da Corte a família Medici criou condições que contribuíram para sua inserção, em 1616, como membro oficial da Academia de Desenho de Florença $^{16}$ - uma instituição criada por Giorgio Vasari em 1563; o que lhe garantiu a possibilidade de abrir o próprio ateliê e contratar modelos.

A saída repentina de Artemisia da cidade florentina, em 1620, se deu devido a questões financeiras, de acordo com Francesco Solinas (2011). O acúmulo de dívidas decorrente de um contrato de trabalho mal pago pelo Grão-Duque Cosme II de Medici, que se encontrava muito doente e debilitado devido à tuberculose, trouxe problemas econômicos e sua situação em Florença ficou insustentável, conforme declara Solinas (2011, p. 79).

O mesmo autor ainda ressalta a necessidade de uma licença concedida pelo GrãoDuque para um artista da corte sair da cidade florentina legalmente. Todavia, o consentimento do líder político não era o suficiente para se obter a autorização para fazer uma viagem, no caso de uma mulher. Segundo Solinas (2011), com exceção das viúvas mais ricas e poderosas, era apenas sob a tutela de um homem, marido, pai, irmão, cunhado ou filho, que se autorizava uma viagem como aquela realizada em 1620 por Artemisia, cujo marido a acompanhou no percurso.

Para interromper seu contrato de trabalho com o Grão-Duque, Artemisia escreveu uma carta, datada de 10 de fevereiro de 1620, a Cosme II de Medici, anunciando sua intenção de passar alguns meses em Roma e justificou sua viagem mencionando problemas familiares.

\footnotetext{
${ }^{15}$ SOLINAS, Francesco (Org). Lettere di Artemisia. Roma: De Luca Editori d' Arte, 2011.

${ }^{16} \mathrm{Em} 19$ de julho Artemisia torna-se membro da Accademia del Disegno de Florença. (Archivio di Stato di Firenze, AD, Entrata et Uscita: Entrata e dal 1602 al 1624, CIII, f. 54).
} 
Entretanto, para Solinas (2011), o argumento da pintora foi um pretexto para obter a autorização do Grão-Duque, pois na carta enviada ao aristocrata florentino Francesco Maria Maringhi (1593-1653), escrita no vilarejo de Prato, durante a viagem para Roma, Artemisia afirmou que não retornaria à Florença. A cidade com vida artística e intelectual intensa, na qual Artemisia chegou com o marido em 1613, já não garantia sucesso econômico como antes e os pagamentos das encomendas já não eram tão privilegiados para os artistas da corte.

De acordo as pesquisas de Solinas (2011, p. 84), antes de voltar para Roma, Artemisia havia dado à luz a quatro filhos, nascidos entre os anos de 1613 e 1618 - Giovan Battista ${ }^{17}$, Cristofano $^{18}$, Prudenzia ${ }^{19}$ e Lisabella ${ }^{20}$. O primogênito e a caçula já haviam falecido em 1620. Quando Artemisia e o marido saíram de Florença, os dois filhos Cristofano e Prudenzia ficaram sob os cuidados de Francesco Maria Maringhi, conforme indica a carta de treze de fevereiro de 1620, quando a pintora solicitou que Maringhi lhe enviasse os filhos com urgência. Artemisia pediu que o amigo lhe mandasse também alguns quadros inacabados, encomendados pelo Grão-Duque, os quais também estavam na residência florentina de Maringhi.

A perda do filho Cristofano, na época com cinco anos de idade, é relatada numa carta de onze de abril de 1620, endereçada a Francesco M. Maringhi. É a partir de 1620 que Artemisia passa a receber frequentes encomendas de cardeais e jovens mulheres de famílias nobres, que a procuravam para encomendar retratos, afirma Solinas (2011). O historiador da arte ressalta que para dar conta da intensa rotina de trabalho no ateliê, Artemisia contratou assistentes que lhe preparavam as telas e as cores, como foi o caso de Alessandro Bardelli.

A partir de 1623 não há mais indícios da presença de Pietro A. Stiattesi junto à sua esposa Artemisia. Segundo os estudos de Francesco Solinas (2011, p. 90), a pintora continuou vivendo em seu apartamento, conforme o censo romano: “[...] com a "senhora Artemisia Lomi romana pintora" moram os dois irmãos Giulio e Francesco, a filha Prudenzia e dois

\footnotetext{
${ }^{17}$ Batizado em setembro de 1613 na Igreja de Santa Maria Novella, em Florença. No documento, a pintora é chamada “Artemisia d'Oratio Gentileschi”. (Archivio dell'Opera del Duomo di Firenze, Registro di Battesimo, Maschi 1612-1613, f. 108v.

${ }^{18}$ Batizado, no dia 9 de novembro de 1615 na Igreja de Sant'Ambrogio, em Florença. (Archivio dell'Opera del Duomo di Firenze, Registro di battesimo, Maschi, 1641-1615, f. 74.

${ }^{19}$ Batizada em agosto de 1617 na Igreja de San Salvatore al Monte, em Florença. O padrinho é o cavaleiro Silvio Piccolomini. (Archivio dell'Opera del Duomo di Firenze, Registro di battesimo, Femmine, 1616-1617, f. 59v In.: NICOLACI, 2011, p. 261). A filha, que recebeu o nome da avó materna é a única a sobreviver à infância. Prudenzia esteve com a mãe em Roma e Nápoles, casou-se em 1636.

${ }^{20}$ Batizada em outubro de 1618 na Igreja de Santa Lucia em Prato. (Archivio dell'Opera del Duomo di Firenze, Registro di battesimo, Femmine 1618-1619, f. 29v.
} 
criados" $^{21}$. O censo efetuado durante a quaresma de 1626 foi o último testemunho da presença de Artemisia em Roma, com a filha e a criada Domenica ${ }^{22}$. Entre 1627 e 1628, sua presença é documentada em Veneza, onde a pintora viveu alguns anos e de onde partiu em 1630 fugindo de uma epidemia de peste, passando a viver em Nápoles ${ }^{23}$. As cartas escritas por Artemisia a partir de 1630 sinalizam que sua produção pictórica não foi discreta. Recebeu diversos pagamentos pelas obras registrados em Nápoles ${ }^{24}$.

No dia vinte de julho de 1635, Artemisia escreveu para o Grão-Duque Ferdinando II de Medici, na época com 18 anos de idade, informando-o que seu irmão Francesco chegaria brevemente à cidade. Na mesma carta, Artemisia falou ao Grão-Duque sobre as instruções recebidas de seu pai, Orazio Gentileschi, ordenando-lhe para acompanhá-lo na viagem para a Inglaterra onde trabalhariam para a corte de Charles I. Artemisia indicou a Fernando II que, sem novas encomendas, não teria escolha a não ser partir para Londres, acompanhada por seu irmão Francesco e levando um documento de viagem da duquesa de Sabóia que lhe permitiria passar pela França ${ }^{25}$.

Em outubro de 1635 Artemisia escreveu a Galileu Galilei - o qual já estava no exílio na localidade de Arcetri, nos arredores de Florença - pedindo-lhe para intervir em seu nome. A pintora referia-se aos dois quadros enviados anteriormente para o Grão-Duque Ferdinando II, pelos quais não havia recebido o pagamento. Na carta, a pintora fez amistosa referência à ajuda que o cientista deu a ela no passado - sobre um retrato de Judite, pintado para Cosme II. Ela fez uma comparação entre o silêncio do Grão-Duque e a generosidade de outros soberanos para com ela. Também mencionou as honras e recompensas que recebeu dos líderes mais poderosos da Europa e em particular, do "Duque de Guise [que] como recompensa por uma de minhas pinturas, que meu irmão tinha apresentado a ele, deu-lhe 200 piastras". Este trabalho tem sido identificado como a Clio, hoje em Pisa. Em sua conclusão ao pé da carta, Artemisia pede a Galileu para enviar a sua resposta através do florentino Francesco Maria Maringhi, cavalheiro que estaria provavelmente em Nápoles ${ }^{26}$.

Há uma lacuna na correspondência de Artemisia, entre sua última carta a Dal Pozzo em outubro de 1637 e dezembro de 1639, data de sua primeira carta escrita em Londres. De

\footnotetext{
${ }^{21}$ Archivio Storico del Vicariato di Roma, Status animarum ab Anno 1622 usque ad 1649, S. Maria del Popolo, LXV, 1623, f. II In. NICOLACI, 2011, p. 263.

${ }^{22}$ Archivio Storico del Vicariato di Roma, Status animarum ab Anno 1622 usque ad 1649, S. Maria del Popolo, LXV, 1626, f. 6.

${ }^{23}$ Questões reveladas através das cartas de Artemisia e também presentes nos estudos biográficos de Michele Nicolaci (2011, p. 264).

${ }^{24}$ Banco dello Spirito Santo de Nápoles.

${ }^{25}$ (Archivio di Stato di Firenze, Mediceo, 4157, f. 194).

${ }^{26}$ (Lettere di Artemisia, 2011, no 44, p. 109).
} 
acordo com Michele Nicolaci (2011, pp. 266-267), no início do ano de 1638, depois de casar sua filha - Prudenzia -, e fazer uma série de tentativas frustradas para estabelecer-se em Modena, Florença e Roma, Artemisia se juntou ao seu pai em Londres; ambos trabalham na produção de uma pintura no teto da Casa da Rainha (Queen's House de Inigo Jones) em Greenwich.

Encerramos a apresentação do conteúdo das correspondências de Artemisia com a carta do dia treze de novembro de 1649. A pintora respondeu a um pedido de Antônio Ruffo o qual encomendara duas novas telas, uma para si e outra para um cavalheiro desconhecido de Messina, um Giudizio di Paride (Julgamento de Paris) e uma Galatea (Galateia). Artemisia expressou seu desapontamento com o pedido explícito de Ruffo para que mudasse a composição da Galateia, de modo a evitar demasiada semelhança com a obra de sua coleção, também produzida por Artemisia:

Não precisava exortar-me sobre isto que pela graça de Deus e da Gloriosíssima Virgem vem de uma mulher que é cheia deste mérito, isto é, de mudar temas na minha pintura; e nunca se encontrou nos meus quadros semelhança de criação sendo de uma mesma mão (Lettere di Artemisia, 2011, no 61, pp.133-134). (Tradução de minha autoria).

Artemisia também se posiciona contra a ideia de enviar-lhe um esboço da pintura, recordando um incidente anterior, quando um esboço de um quadro intitulado Delle anime del purgatorio (Das almas do purgatório), enviado pela pintora, de alguma forma acabou nas mãos de outro artista. Quanto ao pagamento, Artemisia aponta com orgulho as suas origens romanas, dizendo:

Considere Vossa Senhoria Ilustríssima, que quando eu peço um preço não faço ao modo de Nápoles, que pedem trinta e depois dão por quatro, [...] eu sou romana, e por isso quero proceder sempre ao modo romano. [...] Encontrará uma força de César na alma de uma mulher (Lettere di Artemisia, 2011, no 61, p. 134). (Tradução de minha autoria).

Tendo em vista nosso trabalho de relacionar a escrita de Artemisia em suas cartas com sua produção pictórica, apresentaremos agora uma reflexão sobre algumas obras da artista. Para a análise das imagens, nos filiamos à metodologia de Luigi Pareyson (1997). Segundo o autor, a obra de arte para ser compreendida "[...] por um lado ela exige ser colocada no seu tempo e interpretada à luz do espírito da época; por outro lado, contribui para dar a conhecer a 
sua época, em todas as suas diversas manifestações espirituais, culturais, morais, religiosas, etc.” (PAREYSON, 1997, p. 126).

A experiência estética possível através da produção pictórica de Artemisia, ou seja, a relação entre o historiador que olha e o objeto imagético - o qual acaba se transformando num sujeito, pois comunica algo, interage com aquele que olha e interfere nas formas de ver -, faz das imagens não apenas suportes para uma investigação. As relações que se estabelecem, entre o olhar generificado e a pintura, nos forçam a conversar com as imagens ou ainda nos obrigam a perguntar a elas sobre sua própria história. Nesse sentido, nos parece importante a afirmação de Pareyson: “[...] a obra reimerge na história: longe de reduzir-se a um simples momento do fluxo temporal, é capaz de, ela própria, produzir história" (PAREYSON, 1997, p. 133).

A afirmação de Ulpiano B. T. de Meneses igualmente nos ajuda a refletir. Para o pesquisador, “[...] a imagem, também age, executa o papel de ator social, produz efeito" (MENESES, 2005, p.11). Para além de representar um acontecimento, acreditamos que “[...] as imagens não estão na parede (ou na tela), nem apenas na cabeça, mas elas acontecem, têm lugar" (MENESES, 2012, pp. 248-249).

Selecionamos para o presente trabalho, duas versões do título "Judite degolando Holofernes". A primeira versão produzida entre os anos de 1612 e 1613 - atualmente a obra está num acervo na cidade de Nápoles; e a segunda versão de Judite, hoje num acervo florentino, produzida entre os anos de 1620 e 1621.

As duas telas possuem a perspectiva de autorretrato, o que, aliás, perpassa toda a obra de Artemisia. A "Judite decapitando Holofernes", produzida alguns anos depois de se mudar para Florença, entre 1620 e 1621, apresenta uma Judite determinada e menos jovem da Judite finalizada em 1613, período ainda muito marcado pelo desenrolar do processo crime aberto por Orazio Gentileschi contra Agostino Tassi em vista do desvirginamento forçado de Artemisia. As obras citadas fazem parte de um grupo de pelo menos cinco versões de Judite decapitando Holofernes ou carregando sua cabeça num cesto. O conjunto de telas pode ser incluído numa seleção de quadros de Artemisia onde a expressão da violência é fortemente evidenciada.

Figura 1: Giuditta che decapita Oloferne (1612-1613). 


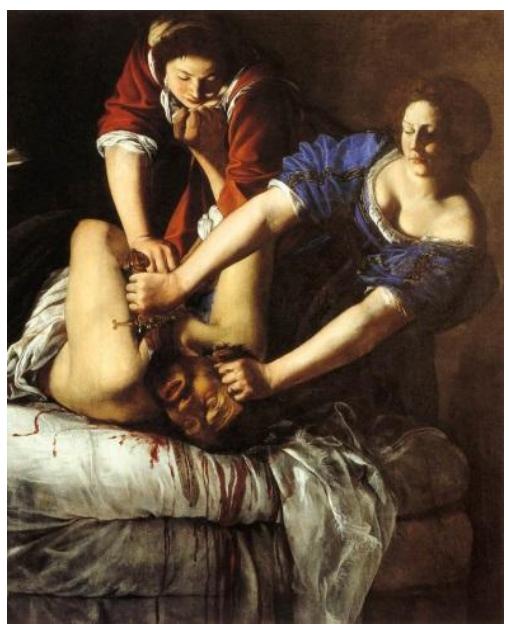

Óleo sobre tela, 158,8 x 125,5 cm. Artemisia Lomi Gentileschi. Museo e Gallerie Nazionali di Capodimonte, Nápoles.

Figura 2: Giuditta che decapita Oloferne (1620-1621).

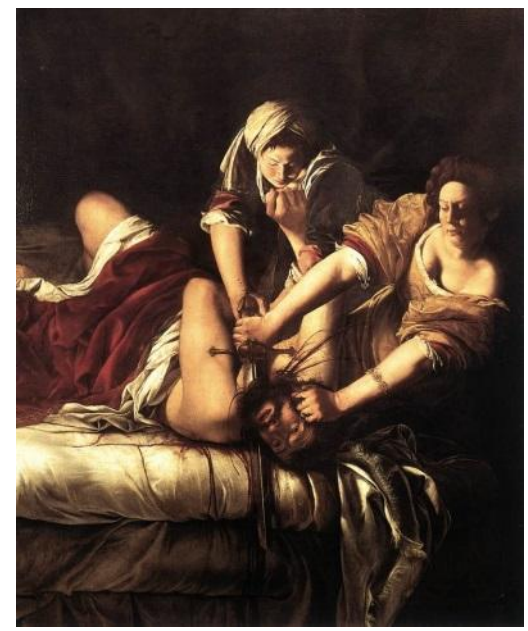

Óleo sobre tela, 199 x 162 cm. Artemisia Lomi Gentileschi. Galleria degli Uffizi, Florença.

Numa leitura dos quadros, podemos perceber que na figura 1 Judite é muito jovem; já na pintura de 1620 (figura 2) a personagem possui braços fortes e está profundamente envolvida no ato de decapitação de Holofernes, respingos de sangue atingem seu peito e seu vestido. Os rostos de Judite e de sua serva, levemente enrugados confirmam que não são as jovens mulheres da primeira imagem. Na figura 2, Judite é apresentada com cabelos muito disciplinados e um bracelete dourado com pedrarias.

Sobre a tela de 1612-13 (figura 1), Judith Mann (2011) afirma,

A pintura sofreu com abrasão e limpezas corrosivas. As áreas sombreadas estão deterioradas, e a espada está agora translúcida. A tela foi reduzida em um lado, e talvez no passado fosse mais parecida com a versão do Uffizi [figura 2], mais simétrica, mas sobre isto os estudiosos não concordam. Bissell (1999) resume todos os pontos relativos à tentativa de reconstruir a 
pintura. A Garrard (1989) é a favor de uma composição mais equilibrada, enquanto Papi (1991) assume que Artemisia pensou os dois quadros como composições diferentes, com diferentes sensibilidades (MANN, 2011, p. 154). (Tradução de minha autoria).

A mesma autora destaca que as figuras humanas de aparência quase pálida são atingidas por uma luz que vem do lado esquerdo e fixa a impressão de luta entre os três personagens - evidenciado também pelos lençóis desfeitos. Além disso, o enquadramento apertado aumenta o poder da imagem. Para Mann (2011), a tela de 1612-13 (figura 1), muitas vezes incluída nos livros de história da arte, tornou-se uma imagem que influenciou profundamente a leitura da arte de Artemisia e deu origem a uma variedade de interpretações.

A pesquisadora Mary D. Garrard (1989), uma das responsáveis pela reconstituição biográfica de Artemisia, cujo trabalho inaugurou uma nova perspectiva sobre a pintora, até então lembrada como mera discípula do pai, realizou uma leitura minuciosa da Judite de 1621 (figura 2). Ao ampliar a imagem, Garrard notou que no bracelete de Judite havia medalhões com figuras femininas em cenas de caça. Esses elementos são importantes para pensar a linguagem estética de Artemisia e reforçam o espírito anticonformista de sua obra.

De acordo com os estudos recentes de Judith W. Mann (2011, p. 58), a historiografia da arte associa a elaboração da tela de 1612 (figura 1) com o período vivido pela artista. Para a mesma autora, o que raramente foi notado na sua produção e que causa ainda mais impacto, é a notável abordagem realizada por Artemisia. A artista narra a história bíblica de Judite superando um dos maiores desafios para um artista: a criação de uma figura humana em movimento.

A crua ostentação do sangue nas produções de Artemisia confere às suas telas duas das representações mais violentas da história de Judite. Artemisia cria sua própria interpretação do tema bíblico do Antigo Testamento. A obra da artista mostra duas mulheres desafiando o poder masculino, diferente das Judites de artistas como Botticelli, Veronesi ou Caravaggio, que não fogem à regra de pintar mulheres delicadas, passivas e frágeis.

Nas duas imagens, Artemisia veste as personagens com a roupagem mais sofisticada de seu tempo. Entretanto, em relação à figura 2, a posição social ocupada por Artemisia no período entre 1613 e 1620, bem como o fato da pintura ter sido encomendada pela corte da família Medici, são questões que podem ter sido decisivas para a criação de alguns elementos presentes na obra, como por exemplo, as vestes em tons dourados e o bracelete de ouro de Judite. 
De acordo com Francesco Solinas (2011), quando a tela "Judite e a criada" (figura 2) foi transportada do Palazzo Pitti para a Galleria degli Uffizi, em 1774, a obra ainda era atribuída a Michelangelo Merisi, o Caravaggio - a assinatura ARTEMITIA LOMI não havia sido notada. O mesmo autor salienta que a tela é um dos mais expressivos trabalhos de Artemisia, no qual a pintora explora o jogo de luzes e sombras. Para Solinas (2011) não são apenas as cores e os drapeados das vestes das personagens que se diferenciam nas duas imagens, mas principalmente suas atitudes. Além disso, o historiador da arte destaca que a pintura (figura 2) é mais sintuosa não só pela maior integridade da superfície da imagem e pelo maior estado de conservação, mas pela sua composição meticulosa e atenta. Estudado e menos imediato é o movimento das figuras humanas, pensado pela artista de modo a conferir força e dinamismo ao corpo de Judite, elementos que acentuam o esforço da personagem no momento da decapitação (SOLINAS, 2011, p. 176).

Conforme Judith Mann (2011), no Medievo tardio e no Renascimento, Judite era retratada como uma heroína virtuosa. Encarnava virtudes nobres como a coragem e a castidade e era associada à Virgem Maria. Mann (2011, p. 154) destaca que a imagem (figura 2), provavelmente foi pintada a partir de um desenho de Artemisia, no qual o posicionamento dos personagens confere à cena o sentido de um evento observado, o que põe em destaque todo o horror e a coragem da ação executada por Judite e sua criada. As duas mulheres da imagem transmitem a ideia de um poder feminino e preanunciam a dramaticidade intensa do alto barroco.

Judith Mann (2011), também destaca alguns estudos psicanalíticos que propuseram diversas associações para entender a forte violência da imagem, incluindo referências ao parto e à castração. Contudo, nosso estudo aproxima-se da interpretação de Keith Christiansen (2001), pois sustentamos a ideia de que a obra, "Judite degolando Holofernes" (figura 1) representa o momento em que a jovem artista se distancia da técnica pictórica do pai e, portanto, pode ser considerada uma importante afirmação de independência.

Ao avaliarmos o conjunto da obra de Artemisia Lomi Gentileschi entendemos que sua linguagem foi muito além do limite de uma representação da violência do desvirginamento. Para Christiansen (2001),

Não devemos subestimar o papel da raiva na obra de Artemisia - não contra Tassi simplesmente (sua raiva em relação a ele implicava um sentido de traição que se estendeu muito além do estupro), mas também contra seu pai e as circunstâncias de sua vida, tanto profissional como privada (CHRISTIANSEN, 2001, p. 111). (Tradução de minha autoria). 
A pintura de Artemisia explora os temas bíblicos, históricos e mitológicos, desenvolvendo uma experiência estética inovadora. A artista apresenta heroínas, matronas, santas e rainhas a partir de uma perspectiva na qual as paisagens e ambientações naturais são substituídas pelo aumento da dimensão dos corpos aliado às sombras intensas com pequenas réstias de luz artificial. Segundo Roberta Genova (2003), essa técnica confere dinamismo às figuras e conduz o olhar do espectador em seu percurso de leitura. Para a mesma autora, esses elementos trazem sobre a superfície bidimensional as inscrições de subjetividade e intersubjetividade. É uma linguagem comunicativa que contribui para sustentar a hipótese de uma complexa ligação entre a vida e a obra de Artemisia. As figuras femininas abandonam o apelo à sensualidade, à beleza e à nudez para ocuparem posições dominantes nas telas de Artemisia Gentileschi. A artista reinterpreta modelos iconográficos anteriores, criando imagens de mulheres imponentes.

Nesse sentido, as problematizações possíveis a partir do conceito de gênero, nos ajudam a entender algumas questões. Levamos em consideração as reflexões de Carla B. Pinsky, quando afirma que podemos investigar as fontes, procurando:

[...] detectar as atuações e performances dos atores históricos, submissas e/ou rebeldes aos limites sociais. Práticas, reinterpretações, tensões e conflitos presentes na vida dos sujeitos históricos emergem muitas vezes das entrelinhas e se revelam diante do olhar de um leitor mais atento (PINSKY, 2009, p. 178-179).

Para Pinsky, "A questão central a ser respondida pelos pesquisadores parte do "como": como, em situações concretas e específicas, as diferenças sexuais são invocadas e perpassam a construção das relações sociais"? (PINSKY, 2009, p. 164). As fontes históricas analisadas têm demonstrado que Artemisia Gentileschi se revela uma artista não conformada com os limites de sua época, ainda que estivesse, assim como todas as mulheres de seu tempo, sendo atingida por discursos direcionados ao seu corpo.

O discurso produzido nas duas representações pictóricas intituladas "Judite decapitando Holofernes" revela um corpo feminino diferente, não é apresentado apenas enquanto um objeto destinado à contemplação visual dos olhares masculinos. Diferentemente de uma série de imagens produzidas por pintores no mesmo período, em que as artes contribuem para solidificar mulheres passivas e submissas ao olhar, as obras de Artemisia propõe uma postura diferente para as mulheres. A releitura da cena bíblica pela pintura de Artemisia pressupõe uma Judite completamente reinventada. 


\section{CONSIDERAÇÕES FINAIS}

O trabalho com as fontes escritas e imagéticas têm mostrado que Artemisia desenvolveu, na primeira metade do século XVII, uma linguagem pictórica inovadora, reinterpretando modelos iconográficos e ressignificando a estética feminina em suas imagens. Sua obra e sua correspondência denunciam o quanto a artista e seu tempo são reveladores de uma feminilidade rebelde que se debate sobre o lugar que ocupa no tecido social. Encontramos nas imagens de Artemisia manifestações de uma profunda inquietação diante do real, não apenas em suas pinturas, mas também em seus depoimentos durante o processo crime e nas cartas que escreveu ao longo de sua vida.

A pintora constitui um dos casos mais conhecidos de participação feminina na arte pictórica barroca do século XVII. Partindo da afirmação: “Artemisia, porém representa somente a ponta do iceberg, o caso mais conhecido ${ }^{27 "}$ (PAGANI, 2003, p. 1), podemos nos perguntar se outras mulheres teriam lutado por um espaço entre as profissões artísticas no período Barroco, contrariando as normas dirigidas a elas pelos discursos. São alguns dos nossos questionamentos que nos permitem reafirmar a importância do olhar microscópico da sociedade, aqui efetivado através do estudo sobre a trajetória de Artemisia e a rede de relações por ela estabelecida.

Procuramos salientar que a atuação de Artemisia não a torna nem vítima nem heroína de sua época, mas sim uma mulher de seu tempo que não deixou de viver em lugares desafiadores. Uma conclusão inacabada permite dizer que as obras pictóricas de Artemisia, bem como sua escrita, manifestam a resistência da artista frente ao mundo masculinizado e patriarcal no qual estava inserida.

\section{REFERÊNCIAS BIBLIOGRÁFICAS}

AGNATI, Tiziana. La fortuna di Artemisia. Art Dossier. Firenze, Giunti, n. 172, novembre, 2001, pp. 5-50.

ARCANGELI, Luciano. Catalogo Artemisia Gentileschi. In. CONTINI, Roberto; SOLINAS, Francesco. Artemisia Gentileschi. Storia di una passione. Catalogo della mostra (Milano, 22 settembre 2011-30 gennaio 2012). Milano: 24 ORE Cultura, 2011, pp. 130-258.

\footnotetext{
27 “Artemisia però rappresenta soltanto la punta dell'iceberg, il caso più conosciuto". (PAGANI, 2003, p. 1). (Tradução de minha autoria).
} 
BARBAGALLO, Sandro. E non dite che dipingeva come un uomo. In.: Mostra Artemisia, Palazzo Reale, Milano, 22 settembre 2011 - 29 gennaio 2012. CL'Oss. Roma, 6 ottobre 2011.

BERTOLOTTI, Antonino. Agostino Tassi: suoi Scolari e compagni pittori in Roma. In. Giornale di erudizione artística, v. fasc. VII-VIII, 1876.

BIUSO, Alberto Giovanni; RANDAZZO, Giuseppina. Artemisia. Rivista di Filosofia Vita Pensata. Ano 2, n. 14, março de 2012, Milão, pp. 50-51. Disponível em: <http://www.vitapensata.eu/vitapensata/wp-content/uploads/2012/03/Rivista-

Marzo_AGBGR_Artemisia.pdf> Acesso em 22 de abril de 2015.

CHARTIER, Roger. À beira da falésia: a história entre certezas e inquietude. Porto Alegre: UFRGS, 2002.

CHRISTIANSEN, Keith. Becoming Artemisia: Afterthoughts on the Gentileschi Exhibition. In.: Metropolitan Museum Journal 39: (C) The Metropolitan Museum of Art, 2001.

CONTINI, Roberto. "Quello che sa fare una donna": Napoli, anni Quaranta, pp. 109-117. In. CONTINI, Roberto; SOLINAS, Francesco. Artemisia Gentileschi. Storia di una passione. Catalogo della mostra (2012). Milano: 24 ORE Cultura, 2011.

; SOLINAS, Francesco. (Org.). Artemisia Gentileschi. Storia di una passione. Catalogo della mostra (2012). Milano: 24 ORE Cultura, 2011.

CONTINI, Roberto; PAPI, Gianni (Org.). Artemisia. Firenze: Leonardo de Luca, 1991.

GENOVA, Roberta. Tracce di enunciazione nella pittura di Artemisia Gentileschi. In: Cultura Visuale. Cultura visuale. Dipartimento di Arti e Comunicazioni dell'Università di Palermo, 2003, pp. 1-31.

GARRARD, Mary D. Artemisia Gentileschi: the image of the female hero in italian Baroque art. New Jersey: Princeton University Press, 1989.

GOMES, Angela M. de Castro. (Org.). Escrita de si, escrita da história. RJ: FGV, 2004.

LONGHI, Roberto. Gentileschi padre e figlia. In. L'Arte, n. 19, 1916, pp. 245-314.

LOPONTE, Luciana Gruppelli. Sexualidades, artes visuais e poder: pedagogias visuais do feminino. Estudos feministas, Florianópolis, 2002. Ano 10, pp. 283-300.

MANN, Judith W. Artemisia Gentileschi nella Roma di Orazio e dei caravaggeschi: 16081612, pp. 51-61 e 130-258. In. CONTINI, Roberto; SOLINAS, Francesco. Artemisia Gentileschi. Storia di una passione. Catalogo della mostra. Milano: 24 ORE Cultura, 2011.

MENESES, Ulpiano T. Bezerra. História e imagem: iconografia/iconologia e além. In: CARDOSO, Ciro Flamarion; VAINFAS, Ronaldo. (Org.). Novos domínios da história. Rio e Janeiro: Elsevier, 2012, pp. 243-262. 
. Rumo a uma história visual. In: MARTINS, J. S.; ECKERT, C.; NOVAES, S. C. (Org). O imaginário e o poético nas Ciências Sociais. Bauru, SP: EDUSC, 2005.

MENZIO, Eva. (Org.). Lettere precedute da «Atti di un processo per stupro». Roma: Abscondita, 2004.

NICOLACI, Michele. Profilo biografico di Artemisia Gentileschi. Roma 1593 - Napoli dopo il 1654, pp. 258-269. In. CONTINI, Roberto; SOLINAS, Francesco. Artemisia Gentileschi. Storia di una passione. Catalogo della mostra. Milano: 24 ORE Cultura, 2011.

PAGANI, Ilaria. Cultura artistica al femminile tra XVI e XVII secolo. In.: Storiadelmoondo, n. 4, 24 febbraio 2003. Disponível em < http://www.storiadelmondo.com/4/pagani.artiste.pdf $>$ Acesso em 8 de abril de 2015.

PAREYSON, Luigi. Os problemas da estética. 3 ed. São Paulo: Martins Fontes, 1997.

PINSKY, Carla Bassanezi. Estudos de Gênero e História Social. Revista de Estudos Feministas. Florianópolis, v 17, n. 1, pp. 159-189, janeiro-abril/2009.

ROCHA, Maria. Artemisia Gentileschi: o empoderamento pela arte ou a sibila de uma nova era. In.: RAGO, Margareth; MURGEL, Ana. (Org.). Paisagens e tramas: o gênero entre a história e a arte. SP: Intermeios, 2013.

SCOTT, Joan. Gênero: Uma categoria útil de análise histórica. Revista Educação e Realidade, Porto Alegre, v 16, n. 2, pp. 05-22, jul-dez/1990.

SOLINAS, Francesco (Org). Lettere di Artemisia. Roma: De Luca Editori d' Arte, 2011.

TEDESCO, Cristine. "E non dite che dipingeva come un uomo”: história e linguagem pictórica de Artemisia Lomi Gentileschi entre as décadas de 1610 e 1620 em Roma e Florença. 2013. 193f. Dissertação (Mestrado) - Programa de Pós-Graduação em História. Universidade Federal de Pelotas, Pelotas. Disponível em:

$<$ http://www2.ufpel.edu.br/tede/tde busca/arquivo.php?codArquivo=1581 > Acesso em $18 \mathrm{de}$ março de 2015.

VIEIRA, Miriam de Paiva. Alegorias contemporâneas: (auto)retratos por Anna Banti, Susan Vreeland e Artemisia Gentileschi. Revista Scripta Uniandrade, v. 10, n. 2, jul.- dez. 2012.

ARTIGO ENVIADO EM: 10/04/2015

ACEITO PARA PUBLICAÇÃO EM: 14/05/2015 